\title{
Determination of soluble toxic arsenic species in alga samples by microwave-assisted extraction and high performance liquid chromatography-hydride generation-inductively coupled plasma-atomic emission spectrometry
}

\author{
S. García Salgado, M.A. Quijano Nieto, M.M. Bonilla Simón* \\ Departamento de Ingenieria Civil: Tecnología Hidráulica and Energética, Escuela Universitaria de Ingenieros Técricos de Obras Públicas, \\ Universidad Politécnica de Madrid, Alfonso XII 3 y $5,280 / 4$ Madrid. Spain
}

\begin{abstract}
A microwave-based procedure for arsenic species extraction in alga samples (Sargassum fulvellum, Chlorella vulgaris, Hizikia fusiformis and Laminaria digitata) is described. Extraction time and temperature were tested in order to evaluate the extraction elficiency of the process. Arsenic compounds were extracted in $8 \mathrm{ml}$ of deionised water at $90^{\circ} \mathrm{C}$ for $5 \mathrm{~min}$. The process was repeated three times. Soluble arsenic compounds extracted accounted for about $78-98 \%$ of total arsenic. The results were compared with those obtained in a previous work, where the extraction process was carried out by ultrasonic focussed probe for $30 \mathrm{~s}$. Speciation studies were carried out by high performance liquid chromatography-hydride generation-inductively coupled plasma-atomic emission spectrometry (HPLC-HG-ICP-AES). The chromatographic method allowed us to separate As(III), As(V), monomethylarsonic acid and dimethylarsinic acid in less than $13 \mathrm{~min}$. The chromatographic analysis of the samples allowed us to identify and quantily As(V) in Hizikia sample and Sargasso material, while the four arsenic species studied were found in Chlorella sample. In the case of Laminaria sample, none of these species was identified by HPLC-HG-ICP-AES. However, in the chromatographic analysis of this alga by HPLC-ICP-AES, an unknown arsenic species was detected.
\end{abstract}

Keywords: Soluble toxic arsenic species; Microwave-assisted extraction; Algae; HPLC; Hydride generation; ICP-AES

\section{Introduction}

Arsenic is a toxic element widely encountered in the environment and organisms [1]. Its speciation has received significant attention over the last years due to its species-dependent toxicity [2]. The inorganic arsenic species [arsenite, As(III), and arsenate, As(V)] have been classified as carcinogenic, and the methylated forms (monomethylarsonic acid, MMA, and dimethylarsinic acid, DMA) have recently been identified as cancer promoters. However, others highly methyl substituted, such as arsenobetaine (AsB) and arsenocholine (AsC), are considered to be non-toxic [2].
Different inorganic and organic arsenic species have been reported in marine organisms, which can accumulate high arsenic concentrations. Depending on the kind of organism, different kinds and concentrations of arsenic compounds are observed. For instance, in marine algae arsenosugar compounds (derivatives of dimethylarsonylribosides and trimethylarsonioribosides), which are considered to be non-toxic, are most abundant [2]. However, some algae are known to contain high percentages of the potentially toxic inorganic arsenic. Therefore, since arsenic species have different toxicity, information about the speciation and distribution of the species within algae will not only help to understand how algae transform and metabolise arsenic, but is also necessary for assessing the risk associated with the entry of arsenic into the wildlife and human food chains [3].

Algae are very popular in the Chinese and Japanese cuisine [4]. Nowadays, their use is widespread in Occidental countries 
due to their high mineral content and their recognized therapeutic properties. The high arsenic levels (several milligrams per kilogram) present in some kinds of algae make necessary the determination of total arsenic concentration, as well as the evaluation of the arsenic species present in commercial brands of algae.

Detailed information concerning analytical methods for arsenic speciation can be found in several reviews [5-7]. The analytical speciation of arsenic has been achieved with the use of hyphenated techniques, i.e. a chromatographic system coupled to an arsenic-selective detector [2,8-12]. The most critical step in the speciation analysis is undoubtedly sample preparation, where it is necessary to extract quantitatively the arsenic species from the complex biological matrix while maintaining the species integrity. In literature, many studies about arsenic extraction in algae can be found, which have used mixtures of water/methanol to extract arsenic species $[5,6,10,13-19]$. Arsenic recoveries are often low and variable, even performing several extraction steps. Conventional sonication is commonly used in order to improve the characteristics of solid-liquid extraction methods $[2,5,10,14-20]$. However, few studies have used accelerated solvent extraction $[5,21]$ or microwave-assisted extraction $[10,22]$, which have shown to give better recoveries than sonication in ultrasonic bath. In a previous work, the convenience of the ultrasonic focussed probe to carry out the extraction of arsenic species in alga samples was shown, which allowed us to reduce the extraction time, with slightly better arsenic recoveries [23]

The aims of this paper consisted on: (1) the optimisation of a microwave-assisted extraction procedure for arsenic speciation in alga samples; (2) the development of an arsenic speciation analysis method based on the coupling of high performance liquid chromatography with hydride generation-inductively coupled plasma-atomic emission spectrometry (HPLC-HG-ICPAES); (3) the identification and quantification of toxic arsenic species present in alga samples by HPLC-HG-ICP-AES.

\section{Experimental}

\subsection{Instrumentation}

A MARS 5 Microwave oven (CEM, Matthews, NC, USA) was used for digestion and extraction of the samples. The temperature was monitored in a control vessel by an armoured fibre-optic temperature control probe. The reaction vessels used were made of Teflon for digestion and Pyrex for extraction procedures, respectively.

An Eppendorf centrifuge $5804 \mathrm{R}$ (Hamburg, Germany) was used for the centrifugation of the alga extracts.

$0.45 \mu \mathrm{m}$ Millipore nylon filters were used to filter all the HPLC solutions, as well as $0.20 \mu \mathrm{m}$ Millex syringe filters to filter the alga extracts before their injection in the HPLC system.

The inductively coupled plasma atomic emission spectrometry instrument used was a Liberty Series II Axial Sequential ICP-AES system (Varian Australia, Mulgrave, Australia). The hydride generation system used was a VGA-77 unit (Varian). Before coupling the chromatographic system, the ICP-AES working conditions were optimised using a standard solution containing $1.0 \mathrm{mg} \mathrm{l}^{-1}$ of manganese. The arsenic signal was then optimised using a $1.0 \mathrm{mg} \mathrm{l}^{-1}$ arsenate standard solution for subsequent HPLC-ICP-AES experiments and a $0.1 \mathrm{mgl}^{-1}$ arsenite standard solution when the hydride generation system was coupled.

The chromatographic system consisted of a Jasco PU-980 HPLC pump (Jasco, Tokyo, Japan) with a Rheodyne 7725 sixport sample injection valve fitted with a $100 \mu \mathrm{l}$ sample loop (Rheodyne, CA, USA). Separations were carried out in a Hamilton PRP-X100 $(250 \mathrm{~mm} \times 4.1 \mathrm{~mm}, 10 \mu \mathrm{m})$ (Phenomenex, Torrance, CA, USA) anion exchange column. A guard column Hamilton PRP-X100 (25 mm $\times 2.3 \mathrm{~mm}, 12-20 \mu \mathrm{m})$ (Phenomenex) was used in order to preserve the analytical column.

The chromatographic system was then coupled to the ICPAES instrument by a polytetrafluoroethylene capillary tube ( $20 \mathrm{~cm}, 0.5 \mathrm{~mm}$ i.d.), which connected the column outlet to the Meinhard nebuliser inlet. When the hydride generation unit was used, the chromatographic system was coupled to the hydride generation unit by the same capillary tube, running from the column outlet to the hydride generation unit inlet.

Chromatographic signals were registered using a Star 800 Module Interface Box and processed using the Star software (Varian). Signal quantification was carried out in the peak area mode.

\subsection{Reagents and standard solutions}

Stock solutions of $1000 \mathrm{mgl}^{-1}$ arsenic were prepared by dissolving the respective amount of the pure compound in deionised water (Milli-Q system, Millipore, USA). As(III) and As(V) standards solutions were prepared from $\mathrm{NaAsO}_{2}$ and $\mathrm{Na}_{2} \mathrm{HAsO}_{4}$, respectively (Panreac, Barcelona, Spain), MMA from $\mathrm{CH}_{3} \mathrm{AsO}_{3} \mathrm{Na}_{2}$ (Supelco, Bellefonte, PA, USA) and DMA from $\left(\mathrm{CH}_{3}\right)_{2} \mathrm{AsNaO}_{2} \cdot 3 \mathrm{H}_{2} \mathrm{O}$ (Fluka, Neu Ulm, Germany). The stock solutions were kept at $4^{\circ} \mathrm{C}$ in the dark. Working solutions were prepared daily and then diluted with deionised water to the final concentration.

The eluent used for the separations was phosphate buffer $(\mathrm{pH}$ 5.5) at a concentration of $17 \mathrm{mM}$. It was prepared by mixing independent solutions of $\mathrm{Na}_{2} \mathrm{HPO}_{4}$ and $\mathrm{NaH}_{2} \mathrm{PO}_{4}$ (Sigma, St. Louis, MO, USA) until the desired $\mathrm{pH}$ was reached.

All HPLC solutions were filtered and degassed before use.

Nitric acid $69.5 \%$ (Scharlau, Barcelona, Spain) was used to digest the samples.

Sodium borohydride solution $0.5 \%(w / v)$ was prepared by dissolving $\mathrm{NaBH}_{4}$ powder (Aldrich, Milwaukee, WI, USA) of $98 \%$ purity in deionised water and stabilising it with $0.5 \%(\mathrm{w} / \mathrm{v})$ sodium hydroxide (Fluka, Neu Ulm, Germany). The resulting solution was filtered and kept at 4 C in the dark. Hydrochloric acid solution $(4.0 \mathrm{M})$ was prepared by dilution of $\mathrm{HCl} 37 \%$ (Scharlau).

\subsection{Alga samples}

The reference material NIES No, 9, certified for total arsenic ( $115 \pm 9 \mu \mathrm{gg}^{-1}$ ), was a lyophilised Sargasso material, 
purchased from National Institute for Environmental Studies (Tsukuba, Ibaraki, Japan). The alga samples analysed were the lyophilised Bioma- 6 material (Chlorella vulgaris), provided by Umweltanalytik-Internationales Hochschulinstitut Zittau (Germany) and Hijiki (Hizikia fusiformis) and Laminaria (Laminaria digitata), acquired in Spanish markets. Commercial products were kept in their packages until their use. Hijiki and Laminaria algae were provided as dry material and capsules, respectively. Hijiki alga was triturated in a mill to a particle size of $125 \mu \mathrm{m}$ and Laminaria capsules were opened and placed in a polyethylene bottle before the analytical treatment.

The total arsenic content in alga samples was determined following the microwave digestion method described in a previous work [23]. The results obtained were $106 \pm 6 ; 88 \pm 6 ; 41 \pm 4$ and $39 \pm 3 \mu \mathrm{gg}^{-1}$ of arsenic for NIES No, 9, Hizikia, Laminaria and Chlorella samples, respectively.

\subsection{Arsenic species determination}

\subsubsection{Microwave extraction procedure}

Approximately, $200 \mathrm{mg}$ of alga sample were accurately weighed into a Pyrex vessel and $8 \mathrm{ml}$ of deionised water were added. The vessel was introduced in the microwave-assisted extraction system and a temperature of $90^{\circ} \mathrm{C}$ was applied for $5 \mathrm{~min}$. Then, the extract was centrifuged for $10 \mathrm{~min}$ at $14,000 \times \mathrm{g}$ and diluted up to $10 \mathrm{ml}$ with deionised water. This extraction process was repeated three times. The supernatants were mixed and total arsenic concentration extracted was determined by ICPAES.

Before the chromatographic analysis, final extracts were centrifuged for $10 \mathrm{~min}$ at $14,000 \times g$ and filtrated with $0.20 \mu \mathrm{m}$ Millex syringe filters.

\subsubsection{Chromatographic separation and detection}

The arsenic species studied (As(III), As(V), MMA and DMA) were separated and detected by HPLC-ICP-AES and HPLC-HG-ICP-AES, using the operation conditions given in

Table 1

ICP-AES, hydride generation and chromatographic operating conditions

\begin{tabular}{|c|c|}
\hline \multicolumn{2}{|l|}{ ICP-AES } \\
\hline Forward power (W) & 1200 \\
\hline Photomultiplier tube voltage (V) & 650 \\
\hline Nebulisation argon pressure $(\mathrm{kPa})$ & 180 \\
\hline Auxiliary argon fow rate $\left(1 \mathrm{~min}^{-1}\right)$ & 1.50 \\
\hline Coolant argon fow rate $\left(1 \mathrm{~min}^{-1}\right)$ & 15.0 \\
\hline Nebuliser type & Meinhard concentric glass \\
\hline \multicolumn{2}{|l|}{ Hydride generation system } \\
\hline Acid solution & $4 \mathrm{M} \mathrm{HCl}$ \\
\hline Reductant solution & $\begin{array}{l}0.5 \%(w / v) \mathrm{NaBH}_{4} \text { (stabilised with } \\
0.5 \%(w / v) \mathrm{NaOH})\end{array}$ \\
\hline Carrier argon pressure $(\mathrm{kPa})$ & 350 \\
\hline \multicolumn{2}{|l|}{ Chromatographic system } \\
\hline Guard column & Hamilton PRP-X100 \\
\hline Analytical column & Hamilton PRP-X100 \\
\hline Mobile phase & Phosphate buffer $17 \mathrm{mM}$ at $\mathrm{pH} 5.5$ \\
\hline Flow rate $(\mathrm{ml} \mathrm{min}-1)$ & 1.0 \\
\hline Injection volume $(\mu \mathrm{l})$ & 100 \\
\hline
\end{tabular}

Table 1. The analytical peaks obtained were evaluated in terms of peak area by external calibration (between 0.1 and $1.0 \mathrm{mg} \mathrm{l}^{-1}$ ) and the standard additions method (between 0.025 and $5.0 \mathrm{mgl}^{-1}$ ) at $193.696 \mathrm{~nm}$ line.

\subsection{Stability of arsenic species during the extraction procedure}

Hizikia sample was spiked with a mixture of the four arsenic species [As(III), As(V), MMA and DMA]. A portion of $200 \mathrm{mg}$ of the alga was weighed and $1 \mathrm{ml}$ of stock solution containing $10 \mathrm{mg} \mathrm{l}^{-1}$ (as arsenic) of each one of the four species was added. The mixture was remained for over night. The spiked sample was taken through the microwave extraction procedure for three times. The arsenic species were then measured by HPLC-HGICP-AES.

\section{Results and discussion}

\subsection{Optimisation of arsenic species extraction}

In a previous work, the convenience of using deionised water as extractant medium was shown, due to the absence of significant improvements in arsenic extraction efficiency with solvent composition. Similar results were obtained by using focussed sonication for $30 \mathrm{~s}$ or magnetic stirring for $30 \mathrm{~min}$, and longer sonication times did not lead to better results. Extraction efficiencies obtained were not higher than $65 \%$ for all kinds of algae analysed [23]. From the results previously obtained, deionised water was selected as extractant medium for further microwaveassisted extraction experiments.

The effect of temperature $\left(50,70\right.$ and $\left.90^{\circ} \mathrm{C}\right)$ and time $(5$, 10 and $20 \mathrm{~min}$ ) for microwave-assisted extraction were studied on Sargasso material. The results are shown in Table 2 as extraction recoveries calculated taking into account the total arsenic concentration of the certified reference material. In the microwave-assisted extraction method, samples need to be sufficiently heated to produce convection currents that shake the tissue and aid in the release of the arsenic species [3]. It is therefore expected that higher temperatures will result in better

Table 2

Total arsenic found in CRM NIES No. 9 (Sargasso) by microwave-assisted extraction, expressed as percentage ( \pm standard deviation, $n=3$ ). depending on temperature and time extraction ( $8 \mathrm{ml}$ of deionised water and three consecutive extraction steps)

\begin{tabular}{lcl}
\hline Temperature $(\sim \mathrm{C})$ & Time $(\mathrm{min})$ & Total as extracted $(\%)$ \\
\hline 50 & 5 & $87 \pm 6$ \\
& 10 & $89 \pm 5$ \\
& 20 & $84 \pm 4$ \\
70 & 5 & $94 \pm 3$ \\
& 10 & $95 \pm 6$ \\
& 20 & $85 \pm 3$ \\
90 & 5 & $98 \pm 5$ \\
& 10 & $95 \pm 5$ \\
& 20 & $93 \pm 4$ \\
\hline
\end{tabular}


Table 3

Total arsenic extracted, expressed as percentage ( \pm standard deviation, $n=3$ ), found in the algac analysed depending on the extraction method used (three consecutive extraction steps with $8 \mathrm{ml}$ of deionised water)

\begin{tabular}{lll}
\hline Alga sample & $\begin{array}{l}\text { Ultrasonic focusscd } \\
\text { probe }(20 \mathrm{kHz} .30 \mathrm{~s})\end{array}$ & $\begin{array}{l}\text { Microwave oven } \\
(90 \text { C. 5 min) }\end{array}$ \\
\hline NlES No. 9 (Sargasso) $^{\mathrm{a}}$ & $65 \pm 3$ & $98 \pm 5$ \\
Hizikia fusiformis & $69 \pm 4$ & $88 \pm 5$ \\
Laminaria digitata & $67 \pm 4$ & $78 \pm 4$ \\
Chlorella vulgarish $^{\mathrm{b}}$ & $64 \pm 3$ & $85 \pm 5$ \\
\hline
\end{tabular}

a Certified value: $115 \pm 9 \mu \mathrm{gg}^{-1}$.

b Two consecutive extraclion steps.

arsenic extraction as long as the extraction temperature does not reach the boiling point of the extractant. This finding is in agreement with the results obtained. Extraction temperature showed a slight improvement of arsenic extraction efficiency at $90^{\circ} \mathrm{C}$, while the effect of extraction time was not significant. Therefore, an extraction time of 5 min was used for further extraction experiments.

In order to evaluate the influenec of alga nature, we procecded to apply the microwave-assisted extraction method developed to the others algac studicd. Table 3 shows the extraction efficiencies, calculated by comparing the arsenic extracted concentration and the total arsenic concentration obtained after the mineralisation of the samples, for the four kinds of algae studied by using $8 \mathrm{ml}$ of deionised water and microwave heating for $5 \mathrm{~min}$ at $90^{\circ} \mathrm{C}$, carrying out three consecutive extraction steps. Total arsenic concentrations found for the third extraction step in Chlorella and Laminaria algae were lower than the detection limit. Therefore, further extraction experiments were carried out by two consccutive extraction sicps for these algac, which also presented a lower total arsenic content. Table 3 also includes the results obtained by $30 \mathrm{~s}$ of ultrasonic focussed probe, in order to compare both extraction methods for all kinds of algae studied. Total arsenic concentration extracted using focussed sonication was close to $65 \%$ of the total arsenic present. However, it reached $78-98 \%$ with microwave irradiation. These recoveries are the best obtained in all the previous tests performed on these algae [23]. In conclusion, for the four kinds of algae studied, a substantial increase in the arsenic extraction efficiency was obtained with the microwave-assisted extraction method, comparing it with the ultrasonic focussed probe. The results showed that the extraction for Sargasso matcrial was quantitative $(98 \pm 5 \%)$.

The final extracts obtained were processed, previously to their chromatographic analysis, through $0.20 \mu \mathrm{m}$ Millex syringe filters. Preliminary studies with standard solutions of the arsenic species studied showed the absence of arsenic losses. In order to clean the extracts, the syringe filters seemed to be inadequate because the filtration of $1 \mathrm{ml}$ sample extract blocked the filters. However, these problems were avoided by a previous centrifugation of the extracts at $14,000 \times \mathrm{g}$ for $10 \mathrm{~min}$.

\subsection{Arsenic species determination}

All extracts were analysed by anion exchange HPLC-HGIPC-AES. The method was designed for the determination of

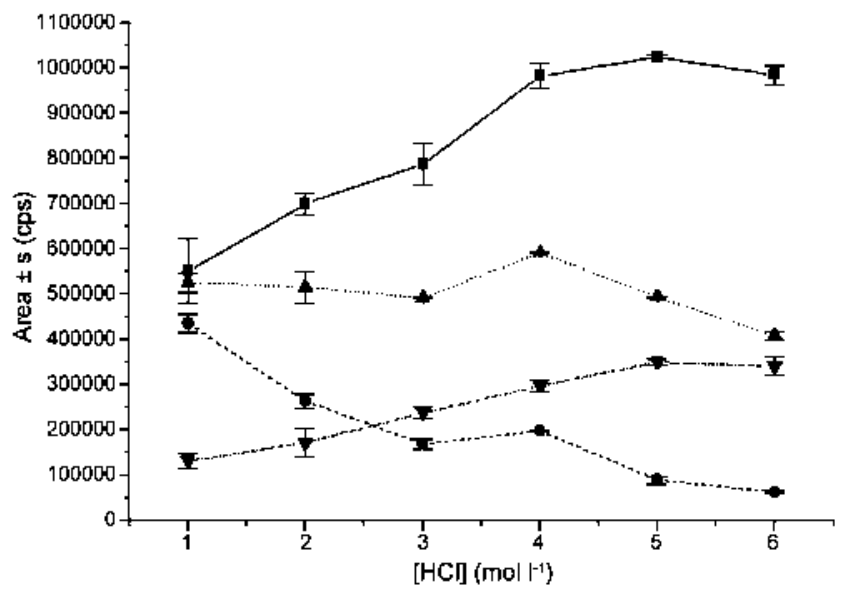

Fig. 1. Effect of $\mathrm{HCl}$ concentration on the signal oblained by HPLC-HG-ICPAES for a standard solution of $100 \mu \mathrm{gl}{ }^{1}$ of arsenic per species [ $\mathrm{As}$ (III); $\mathbf{\nabla}$ $\mathrm{As}(\mathrm{V}) ; \stackrel{\mathrm{MMA}}{\mathrm{O}} \mathrm{DMA}$.

the four arsenic species studied, which are As(III), As(V), MMA and DMA, and which will be called "identified species" hereafter. The likely presence of unidentified arsenic species was investigated by the HPLC-ICP-AES method.

It is well known that the hydride generation efficiency depends on the type of hydride generation system and is influenced by the concentrations of $\mathrm{HCl}$ and $\mathrm{NaBH}_{4}$. In the present work, a hydride generation system purchased from Varian was used, whose specifications are indicated in Section 2. Therefore, the required experiments were carried out in order to optimise the concentrations of $\mathrm{HCl}$ and $\mathrm{NaBH}_{4}$.

Hydrochloric acid concentrations in the range of $1-6 \mathrm{M}$ were tested. The signals obtained for the four arsenic species studied are illustrated in Fig. 1. The experiments were carried out with a solution of $0.5 \%(\mathrm{w} / \mathrm{v}) \mathrm{NaBH}_{4}$. The results showed notable differenees in the hydride generation efficiency for the four arsenic species studied. The signals of the inorganic arsenic species increase with the acidity, while the methylated arsenic species present a different behaviour. From the results obtained, a concentration of $4.0 \mathrm{M} \mathrm{HCl}$ was chosen for further experiments, as situation of compromise between the signals obtained for the four arsenic species studied.

Different sodium borohydride concentrations in the range of $0.3-1.0 \%(\mathrm{w} / \mathrm{v})$ were tested to determine the optimum concentration for the four arsenic species studied. Fig. 2 shows the results obtained. For the four arsenic species studied, the signals increase with $\mathrm{NaBH}_{4}$ concentration. However, at concentration levels close to $0.7 \%(\mathrm{w} / \mathrm{v})$, the plasma became unstable, and for this reason, a $\mathrm{NaBH}_{4}$ concentration of $0.5 \%(\mathrm{w} / \mathrm{v})$ was selected for further experiments.

The carrier gas pressure was optimised by a continuous HGICP-AES determination of the signal/noise ratio for $100 \mu \mathrm{g}^{-1}$ of As(III) standard solution. Maximum signal/noise ratio was achieved at $350 \mathrm{kPa}$ argon pressure, which was therefore used for all further HG-ICP-AES measurements.

Fig. 3 shows the HPLC-HG-ICP-AES chromatogram obtained for a standard solution containing $100 \mu \mathrm{gl}^{-1}$ of arsenic per species (As(III), DMA, MMA and As(V)). Scp- 


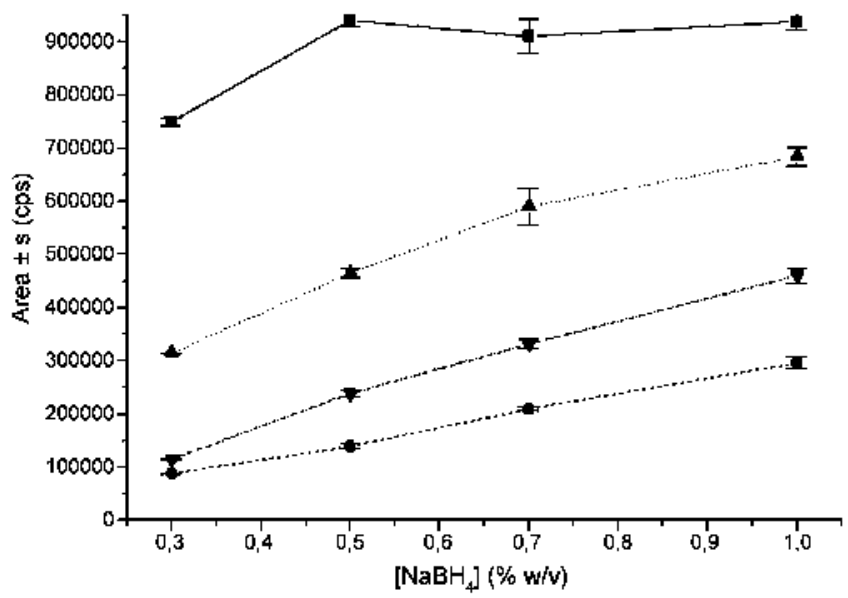

Fig. 2. Effect of $\mathrm{NaBH}_{4}$ concentration on the signal obtained by HPLC-HGICP-AES for a standard solution of $100 \mathrm{\mu g}^{-1}$ of arsenic per species, using 4.0 M HCl [ As(III); $\mathbf{A s}(\mathrm{V}) ; \triangle \mathrm{MMA} ; \mathbf{D M A}]$.

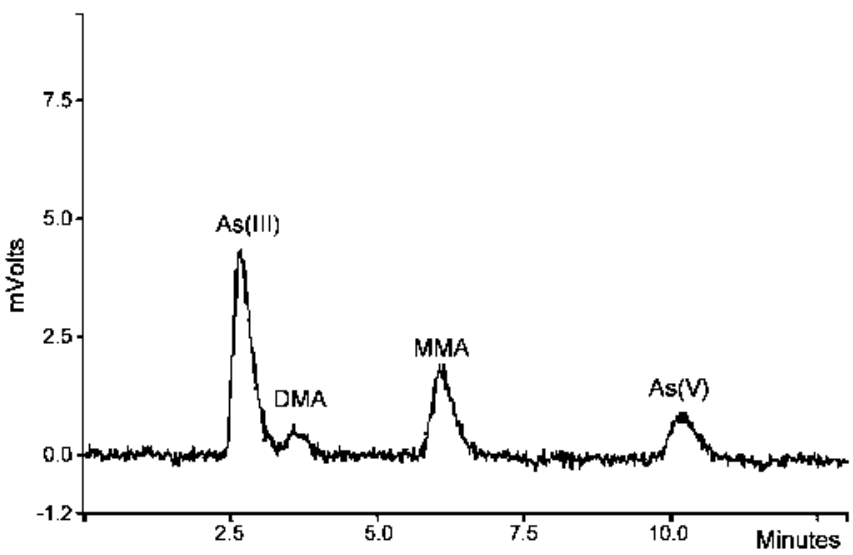

Fig. 3. HPLC-HG-ICP-AES chromatogram obtained for a standard solution containing $100 \mu \mathrm{g}^{-1}$ of arsenic per species.

aration of arsenic species is resolved to baseline in less than $13 \mathrm{~min}$.

The analytical characteristics and the chromatographic parameters of the method were evaluated for the four arsenic compounds and are shown in Table 4 . The precision of the method, evaluated as relative standard deviation, was calculated from five replicate measurements of a solution containing $100 \mu \mathrm{g}^{-1}$ of arsenic per species. The detection limit is defined as three times the standard deviation obtained from ten replicate blank determinations. In this method, the signal from the blank was negligible. Therefore, detection limits were calculated as

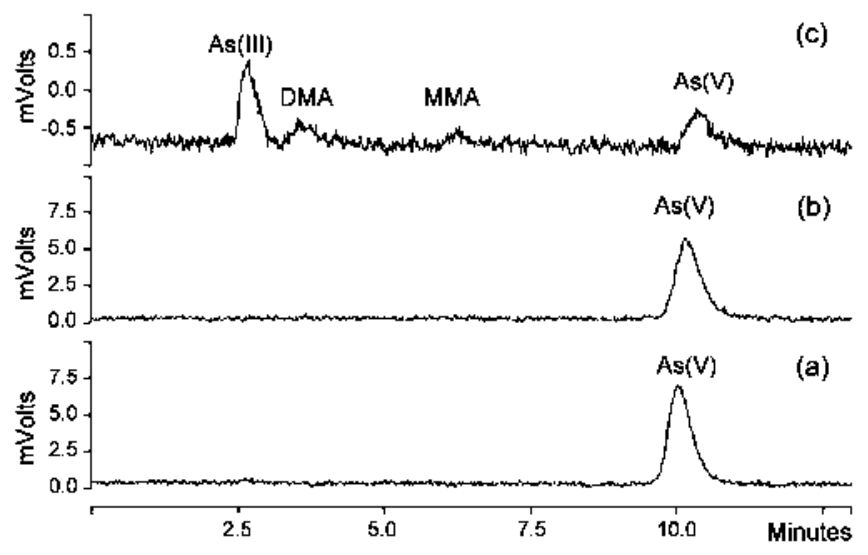

Fig. 4. HPLC-HG-ICP-AES chromatograms obtained for the water extract of Sargassum (a), Hizikia (b) and Chlorella (c) algae.

three times the standard deviation obtained from 10 replicates of the lowest standard used in the calibration curve, which was of $25 \mu \mathrm{g}^{-1}$ arsenic per species and are also shown in Table 4 .

The chromatographic method was applied to the algae studied. The chromatograms obtained for Sargassum, Hizikia and Chlorella algae are shown in Fig. 4. Four peaks can be distinguished in Chlorella chromatogram (Fig. 4c) and one peak in Sargassum and Hizikia chromatograms. The arsenic species were identified due to the increase in their areas when arsenic species standard solutions were added. The four arsenic species studied were found in Chlorella extract (Fig. 4c), while only the species $\mathrm{As}(\mathrm{V})$ was identified in Sargassum and Hizikia samples (Fig. $4 \mathrm{a}$ and $\mathrm{b}$ ). In the case of Laminaria digitata alga, no presence of the arsenic species studied was detected. However, the HPLC-ICP-AES chromatogram for this sample showed the presence of an unknown arsenic species, which eluted in the dead volume and probably could be considered as an arsenosugar [23].

Species quantification by HPLC-HG-ICP-AES was carried out by cxternal calibration and the standard additions method. The absence of matrix effects was checked duc to the absenec of significant differenees, at the $95 \%$ confidenec level, between the calibration slopes obtained by both methods (Table 4). The results of species quantification are shown in Table 5. The concentration of the unknown arsenic species present in Laminaria sample, was estimated by HPLC-ICP-AES as arsenic analyte, by calibration against the nearest neighbouring peak of a known species, which was As(III). The arsenic concentration estimated was $7.0 \pm 1.1 \mu \mathrm{g} \mathrm{g}^{-1}$.

Table 4

Analytical characteristics and chromatographic parameters of HPLC-HG-ICP-AES method for the four arsenic species studied

\begin{tabular}{|c|c|c|c|c|c|}
\hline Species & $k^{\prime}$ & External calibration slopes (cps $\mathrm{mg}^{-1}$ ) & Standard additions calibralion slopes (cps mg ${ }^{-1}$ ) & $\mathrm{DL}^{\mathrm{a}}(\mathrm{ng} \mathrm{As})$ & \%RSD ${ }^{h}$ \\
\hline $\mathrm{As}(\mathrm{III})$ & $0.22 \pm 0.02$ & $(103.3 \pm 1.2) \times 10^{4}(r=0.9998)^{\mathrm{C}}$ & $(93.3 \pm 0.7) \times 10^{4}(r=0.9994)$ & 0.5 & 3.3 \\
\hline DMA & $0.63 \pm 0.03$ & $(14.0 \pm 0.3) \times 10^{4}(r=0.9994)$ & $(13.5 \pm 0.9) \times 10^{4}(r=0.9989)$ & 2.0 & 4.5 \\
\hline MMA & $1.77 \pm 0.03$ & $(53.4 \pm 1.5) \times 10^{4}(r=0.9988)$ & $(45.8 \pm 3.1) \times 10^{4}(r=0.9952)$ & 1.0 & 3.7 \\
\hline
\end{tabular}

\footnotetext{
" Calculated for a standard solution containing $25 \mu \mathrm{g}^{-1}$ of arsenic per species and using a $100 \mu 1$ sample injection volume.

${ }^{\text {th }}$ Calculated for a standard solution containing $100 \mu \mathrm{gl}{ }^{1}$ of arsenic per species.

c $r$ is the correlation cocfficient of regression.
} 
Table 5

Quantitative tesults for arsenic species in alga samples expressed as $\mu \mathrm{g}^{-1}$ of atsenic (mean \pm standard deviation, $n=3$ ), by HPLC-HG-ICP-AES.

\begin{tabular}{|c|c|c|c|c|c|c|}
\hline Sample & As(III) & $\mathrm{As}(\mathrm{V})$ & MMA & DMA & Total as extracted & $\%$ Recovery \\
\hline NIES No. 9 (Sargasso) $^{b}$ & & $72 \pm 3$ & & & $113 \pm 5$ & $64 \pm 3$ \\
\hline Hizikia & & $62 \pm 2$ & & & $77 \pm 3$ & $80 \pm 3$ \\
\hline Chlorella & $6.1 \pm 0.4$ & $11.8 \pm 0.5$ & $2.2 \pm 0.3$ & $15 \pm 2$ & $33 \pm 5$ & $106 \pm 9$ \\
\hline
\end{tabular}

a Calculated by comparing the sum of atsenic species concentrations and the total arsenic concentration in the extract.

b Total arsenic certified material.

Speciation recoveries were calculated by comparing the sum of arsenic species concentrations with the total arsenic concentration found in the extracts. The speciation recovery for Sargasso material was lower than the found for Hizikia and Chlorella algae. For Chlorella sample, all arsenic was extracted and also identified as species. The analysis by HPCL-ICP-AES for Sargasso and Hizikia did not show the presence of another arsenic species, so only As(V) was detected for both samples. Therefore, sample matrix seems to be an important point to consider, since it may cause the retention of the arsenic extracted on the HPLC column [21]. Another explanation for these variations may be the presence of arsenic species at concentration levels lower than the detection limits of the method.

\subsection{Stability of arsenic species during the extraction procedure}

In any elemental speciation study, it is important to investigate whether the individual species are altered during any step of the method. For this purpose, reference materials certified for arsenic species of interest would be ideal. However, the reference materials frequently used in arsenic speciation works have no certified values for the arsenic compounds. Therefore, spiking of alga material was used to evaluate the stability of arsenic species during the extraction procedure.

A mixture of arsenic species [As(III), As(V), MMA and DMA] was added to dried Hizikia material and extracted with $8 \mathrm{ml}$ of deionised water by microwave heating $(90 \mathrm{C})$ for $5 \mathrm{~min}$, carrying out three extraction steps. The recoveries obtained for the three spiked samples studied are shown in Table 6 . The results obtained confirmed the absence of significant losses or transformations of arsenic species evaluated during the sample treatment.

Table 6

Recoveries obtained for three spiked teplicates of Hizikia sample to evaluate the stability of arsenic species during the extraction procedure

\begin{tabular}{lllrr}
\hline Species & $\begin{array}{l}\text { Concentration } \\
\text { ptesent }(\mu g)\end{array}$ & $\begin{array}{l}\text { Concentration } \\
\text { added }(\mu g)\end{array}$ & $\begin{array}{l}\text { Concentration } \\
\text { fond }(\mu g)\end{array}$ & Recovery $^{3}(\%)$ \\
\hline As(III) & - & 10 & $9.51 \pm 0.28$ & $95 \pm 3$ \\
DMA & - & 10 & $9.15 \pm 0.76$ & $92 \pm 8$ \\
MMA & - & 10 & $11.48 \pm 0.87$ & $115 \pm 9$ \\
As(V) & 16.8 & 10 & $26.11 \pm 0.72$ & $93 \pm 7$ \\
\hline
\end{tabular}

a Calculated by comparing the concentration found and the concentration added. In the case of $A s(V)$, the concentration present in the sample must be subtracted to the concentration found.

\section{Conclusions}

The proposed microwave-assisted extraction method of arsenic species from algae samples, using approximately $200 \mathrm{mg}$ of alga and $8 \mathrm{ml}$ of deionised water and applying a temperature of $90^{\circ} \mathrm{C}$ for a time of $5 \mathrm{~min}$, allowed us to achieve an arsenic extracted recovery between 78 and $98 \%$, when three extraction steps were carried out, depending on the kind of alga analysed. These extraction efficiencies obtained were considerably better than those obtained for $30 \mathrm{~s}$ of focused sonication (about $65 \%$ ).

Spiked studies showed that all the arsenic species evaluated remained stable during the extraction procedure, because between 93 and $115 \%$ of the spiked arsenic species were recovered.

The optimised hydride generation conditions for the determination of the four arsenic species studied consisted of $4.0 \mathrm{M}$ $\mathrm{HCl}, 0.5 \%(w / v) \mathrm{NaBH}_{4}$ and $350 \mathrm{kPa}$ argon pressure as carrier gas. Hydride generation in conjunction with ICP-AES enhances considerably the analytical capabilities of ICP-AES for determining toxic arsenic species at trace levels in alga samples with high accuracy.

Chromatographic analysis using HG-ICP-AES as detection method allowed us to identify and quantify As(V) in Hizikia sample $\left(62 \pm 2 \mu \mathrm{g} \mathrm{g}^{-1}\right)$ and Sargasso material $\left(72 \pm 3 \mu \mathrm{g} \mathrm{g}^{-1}\right)$, while all arsenic species studied were found in Chlorella sample, at a concentration level of $6.1 \pm 0.4 \mu \mathrm{gg}^{-1}$ for As(III); $15 \pm 2 \mu \mathrm{gg}^{-1}$ for DMA; $2.2 \pm 0.3 \mu \mathrm{gg}^{-1}$ for MMA and $11.8 \pm 0.5 \mu \mathrm{gg}^{-1}$ for As(V). For Laminaria alga, none of these species was identified by HPLC-HG-ICP-AES. However, in the chromatographic analysis by HPLC-ICP-AES, an unknown arsenic species was detected, which eluted in the dead volume.

From the results obtained for Hizikia alga, which present large quantities of $\mathrm{As}(\mathrm{V})$ and was acquired in food markets, it can be concluded that reliable analytical methods for monitoring the presence of toxic arsenic species in food are required to safeguard human health.

\section{Acknowledgement}

The authors would like to thank "Ministerio de Ciencia y Tecnología" for financial support (project FEDER UPM00-33015).

\section{References}

[1] W. Zhang. Y. Caj, K.R. Downum, L.Q. Ma. J. Chromatogr. A 1043 (2004) 249.

[2] S. Karthikeyan, S. Hitata, Appl. Organomet. Chem. 18 (2004) 323. 
[3] M. Quaghebeur. Z. Rengel, M. Smirk, J. Anal. At. Spectrom. 18 (2003) 128.

[4] K.A. Francesconi. J.S. Edmonds, in: J.O. Nriagu (Ed.). Arsenic in the Envjronment. Part 1. Cycling and Characterization, Wiley, New York. 1994. p. 221.

[5] Z. Gong, X. Lu, M. Ma, C. Watt, X.C. Le. Talanta 58 (2002) 77.

[6] S. McSheehy, J. Szpunar. R. Morabito, Ph. Quevauviller, Trends Anal. Chen. 22 (2003) 191 .

[7] J. Szpunat, Analyst 125 (2000) 963.

[8] S. McSheehy, P. Pohl, D. Vélez, J. Szpunar, Anal. Bioanal. Chem. 372 (2002) 457 .

[9] K.A. Francesconi. Appl. Organomet. Chem. 16 (2002) 437.

[10] R. Tukai, W.A. Maher, I.J. McNaught, M.J. Ellwood, Anal. Chim. Acta 457 (2002) 173.

[11] A. Huerga, I. Lavilla, C. Bendicho, Anal. Chim. Acta 534 (2005) 121.

[12] J. Koh. Y. Kwon. Y.-N. Pak. Microchem. J. 80 (2005) 195.

[13] G. Raber, K.A. Francesconi, K.J. Irgolic. W. Goessler, Fresenius J. Ana]. Chem. $367(2000) 181$

[14] D. Kuehnelt, K.J. Iryolic, W. Goessler, Appl. Orģanomet. Chem. 15 (2001) 445 .
[15] V.W.-M. Lai, W.R. Cullen, C.F. Hartington, K.J. Reimer. Appl. Oryanomet. Chem. 11 (1997) 797.

[16] C.F. Harrington. A.A. Ojo. V.W.M. Laj, K.J. Reimer. W.R. Cullen, Appl. Organomet. Chem. 11 (1997) 931.

[17] V.W.-M. Lai, W.R. Cullen, C.F. Hartington, K.J. Reimer, Appl. Organomet. Chem. 12 (1998) 243.

[18] S. McSheehy, P. Pohl. R. Lobinski, J. Szpunar, Anal. Chin. Acta 440 (2001) 3.

[19] S. McSheehy, M. Marcinek. H. Chassaigne, J. Szpunar, Anal. Chim. Acta $410(2000) 71$.

[20] R. Eisler (Ed.). Handbook of Chemical Risk Assessnent Health Hazards to Humans, Plants and Animals. Metalloids, Radiation, Cunulative Index to Chemicals and Species, 3, CRC Press. Boca Raton. FL, 2000, Chapter 28.

[21] R. Wahlen. S. McSheeby, C. Scrivet, Z. Mester, J. Anal. At. Spectrom. 19 (2004) 876 .

[22] T. Dagnac, A. Padró, R. Rubio, G. Rauret. Anal. Chim. Acta 364 (1998) 19.

[23] S. García Salgado, M.A. Quijano Nieto, M.M. Bonilla Simón, Talanta 68 (2006) 1522 . 